\title{
Interleukin-35 promotes progression of prostate cancer and inhibits anti-tumour immunity
}

Jialin Zhu ${ }^{1+}$, Yan Wang ${ }^{2+}$, Dai $\mathrm{Li}^{3 \dagger}$, Haonan Zhang ${ }^{4}$, Zhi Guo ${ }^{4^{*}}$ and Xueling Yang ${ }^{4^{*}}$ (D)

\begin{abstract}
Background: Interleukin-35 (IL-35) has been reported to play an important role in the progression of cancers. The role of IL-35 in prostate cancer (PCA) is not well understood. In this study, we investigated the effects of IL-35 on PCA and its immunoregulatory effect on PCA.

Methods: The protein and mRNA expression of IL-35 in PCA cells was detected by western blot and RT-PCR. The invasion and migration of cells were detected using transwell and wound-healing assays. A CCK-8 assay was conducted to observe cell proliferation. In vivo, IL-35 plasma concentration was test by enzyme-linked immunosorbent assay. The role of IL-35 in tumour cell proliferation and angiogenesis of mice was detected by immunohistochemical stains. The mouse survival and tumour volumes were calculated, and lung metastasis rate was detected by HE staining. The modulatory effects of IL-35 on myeloid-derived inhibitory cells (MDSCs), regulatory T cells (Tregs), CD4+T cells and CD8+T cells from PCA mice were investigated by immunohistochemical stains and flow cytometry.
\end{abstract}

Results: High levels of IL-35 significantly promoted the migration, invasion and cell proliferation of PCA cells in vitro. IL-35 was associated with tumour growth, metastasis and poor prognosis in PCA mice. Additionally, high levels of IL-35 significantly increased the proportions of MDSCs and Tregs and decreased the proportions of CD4+ and CD8+T cells in the spleen, blood and tumour microenvironment. The IL-35 neutralizing antibody played the opposite role.

Conclusions: IL-35 contributed to the progression of PCA through promoting cell proliferation and tumour angiogenesis. IL-35 might limit the anti-tumour immune response by upregulating the proportions of Tregs and MDSCs and by reducing the proportions of CD4+ and CD8+T cells. IL-35 might serve as a novel therapeutic target for PCA.

Keywords: Interleukin-35, Prostate cancer, Proliferation, Angiogenesis, Anti-tumour immunity

\section{Background}

Prostate cancer (PCA) is the second most common malignant tumour and the fifth leading cause of cancerassociated mortality in men worldwide [1]. Patients with

\footnotetext{
*Correspondence: cjr.guozhi@vip.163.com; yxueling123@163.com ${ }^{\dagger}$ Jialin Zhu, Yan Wang and Dai Li contributed equally to this work

${ }^{4}$ Department of Interventional Therapy, Tianjin's Clinical Research Center for Cancer, Key Laboratory of Cancer Prevention and Therapy, National Clinical Research Center for Cancer, Tianjin Medical University Cancer Institute and Hospital, Huan Hu West Road, Tianjin 300060, China Full list of author information is available at the end of the article
}

localized PCA are usually treated with surgery or radiotherapy. However, $20-40 \%$ of patients receiving radical prostatectomy and $30-50 \%$ of patients receiving radiation therapy will have a recurrence that develops into metastatic disease [2]. At present, there is no ideal treatment for metastatic castrated prostate cancer, and most of the patients have poor prognoses [3]. Therefore, it is urgent to develop a more effective treatment.

In recent years, bio-immunotherapy has become a new therapy that has attracted increasing attention. Studies have shown that some tumour cells evade immune recognition and killing by activating the negative stimulus

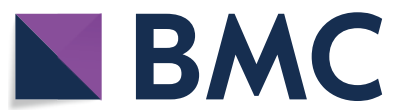

(c) The Author(s) 2020. This article is licensed under a Creative Commons Attribution 4.0 International License, which permits use, sharing, adaptation, distribution and reproduction in any medium or format, as long as you give appropriate credit to the original author(s) and the source, provide a link to the Creative Commons licence, and indicate if changes were made. The images or other third party material in this article are included in the article's Creative Commons licence, unless indicated otherwise in a credit line to the material. If material is not included in the article's Creative Commons licence and your intended use is not permitted by statutory regulation or exceeds the permitted use, you will need to obtain permission directly from the copyright holder. To view a copy of this licence, visit http://creativeco mmons.org/licenses/by/4.0/. The Creative Commons Public Domain Dedication waiver (http://creativecommons.org/publicdomain/ zero/1.0/) applies to the data made available in this article, unless otherwise stated in a credit line to the data. 
signal and by regulating the inhibitory immune response [4]. In addition, tumour cells can recruit immunosuppressive cells, such as regulatory $\mathrm{T}$ cells (Tregs) and myeloid-derived inhibitory cells (MDSCs), and mediate the release of immunosuppressive factors directly or indirectly. Immunosuppressive cells jointly promote the occurrence and development of the immunosuppressive tumour microenvironment and significantly promote tumour progression. Therefore, some cytokines with immunosuppressive functions, such as transforming growth factor (TGF)- $\beta$, interleukin (IL)- 6 , and IL-35, have attracted great attention $[5,6]$.

IL-35 is a newly discovered immunosuppressive cytokine that consists of EBI3 and P35 subunits and belongs to the IL-12 cytokine family [7]. This family has become the focus of tumour biological immune related domain research [8]. Some research has shown that IL-35 is highly expressed in a wide range of tumour tissues, which could promote tumour angiogenesis and inhibit anti-tumour immunity $[9,10]$. In many different types of malignant tumours, plasma IL-35 levels are closely related to tumour stage, tumour size and lymph node metastasis [11, 12]. High expression of IL-35 in tumour tissues and increased expression of IL-35 in plasma suggest poor prognosis of patients [13-16].

The results of current clinical studies on PCA showed that the average concentration of serum IL-35 in patients with PCA was significantly higher than that in healthy controls, indicating that IL-35 may be involved in the tumourigenesis of PCA $[17,18]$. Our previous research shows that increased expression of IL-35 in the plasma and tumour tissues may contribute to the progression and metastasis of PCA patients [17]. However, the expression of IL-35 in different PCA cell lines and the mechanism of how IL-35 effects progression and metastasis of PCA have not been reported. The purpose of this study was to detect the expression of IL-35 in different prostate cancer cell lines, to detect the effects of IL-35 on the biological behaviour of PCA cells, and to explore the effects of IL-35 on tumour proliferation, angiogenesis, metastasis and immune cell populations in PCA mice.

\section{Materials and methods \\ Cell culture}

The human PCA cell lines PC-3, DU145, LNCaP and mouse PCA cell line RM-1 were purchased from Shanghai Institutes for Biological Science of the Chinese Academy of Sciences (Shanghai, China). These cells were cultured in Roswell Park Memorial Institute-1640 medium (RPMI-1640) (Gibco, Carlsbad, CA, USA) or F-12K nutrient medium with $10 \%$ foetal bovine serum at $37^{\circ} \mathrm{C}$ in a humidified atmosphere of $95 \%$ air and $5 \%$ $\mathrm{CO}_{2}$. To investigate the regulatory effect of IL-35 on
RM-1 cells, the cells were divided into NC (double distilled water as a negative control), IL-35 (recombinant IL-35 protein, $200 \mathrm{ng} / \mathrm{ml}$, diluted by double distilled water), Scramble (PBS, as a control group for the IL-35 NA group), and IL-35 NA (anti-IL-12A antibody, $200 \mathrm{ng} /$ $\mathrm{ml}$, diluted by PBS) groups.

\section{Western blot analysis}

For protein extraction, cells or tumour tissues were lysed in RIPA buffer supplemented with a protease inhibitor cocktail (Sigma, USA). A total of $30 \mathrm{mg}$ protein lysate was separated by SDS-PAGE, and then the target proteins were detected by western blot analysis with antibodies against EBI3 (ab83896, Abcam) and p35 (ab66064, Abcam). $\beta$-Actin (ab8227, Abcam) was used as an internal control.

\section{RNA extraction and real-time polymerase chain reaction (RT-PCR)}

Total RNA of the cells was extracted with TRIzol reagent (Invitrogen, USA) according to the manufacturer's instructions. Then, the quantity and purity of RNA was determined by absorbance on a microplate reader (Sunnyvale, USA) at $260 \mathrm{~nm}$ and $280 \mathrm{~nm}$. Samples with ratios from 1.7 to 2.0 were accepted for the next reverse transcription reaction. The mRNA was reverse transcribed to single-stranded complementary DNA by using a RTPCR system (TaKaRa, Japan). Real-time fluorescent quantitative PCR was used to analyse the cDNA levels. The primer sequences are shown in Table1. IL-12 is composed of p35 and p40, and IL-27 is composed of p28 and EBI3. The detection of $\mathrm{p} 40$ and $\mathrm{p} 28$ was to exclude the effects of IL-12 and IL-27.

\section{Cell invasion assay}

The invasive ability of cells was detected in 24-well transwell chambers with $8.0 \mathrm{~mm}$ pore inserts pre-coated with Matrigel. For this assay, the tumour cells were digested and resuspended in FBS-free RPMI-1640 culture medium. A total of $100 \mu \mathrm{l}\left(1.5 \times 10^{5}\right.$ cells per ml of tumour cells was seeded into the upper chamber. The basolateral chambers were supplemented with $60 \mu \mathrm{l} \mathrm{com-}$ plete culture medium (RPMI-1640 with $20 \% \mathrm{FBS}$ ), and the cells were incubated at $37^{\circ} \mathrm{C}$ in $5 \% \mathrm{CO}_{2}$ for $24 \mathrm{~h}$. For

\section{Table 1 Primer sequences used for RT-PCR}

\begin{tabular}{lll}
\hline Genes & Forward sequence & Reverse sequence \\
\hline EBI3 & GATCCGTTACAAGCGTCAGG & CTCAGTTCCCCGTAGTCT \\
p35 & CTCCCTTGAAGAACCGGAT & ATCAATAGTCACTGCCCGAA \\
p40 & CCCTGACATTCTGCGTTCA & AGGTCTTGTCCGTGAAGACTCTA \\
p28 & CAGACGGCAGGCGACCTT & TGACTGTGAACTCCCTCCGC \\
\hline
\end{tabular}


each insert, the invading cells in five random fields of $200 \times$ magnification were counted. Each experiment was performed in triplicate.

\section{Cell migration assay}

The migration ability of prostate cancer cells was detected using a wound healing assay. First, RM-1 cells were seeded in 6-well plates at approximately $80 \%$ confluence. After that, a wound was made in the centre of each well using a $10 \mu \mathrm{L}$ pipette tip. Each well was washed with PBS twice and added to media containing 1\% FBS and different solutions (double distilled water, rhL-35 protein, PBS, or anti-IL-12A antibody). At $0 \mathrm{~h}$ and $48 \mathrm{~h}$, images of the wound area of each well were captured. Cell migration was calculated as the area of cell migration compared to the area of the initial wound. All experiments were repeated three times.

\section{Cell proliferation assay}

Cell proliferation was evaluated by cell-counting kit-8 (CCK-8) (Dojindo, China) according to the manufacturer's manual. In brief, $100 \mu \mathrm{L}$ of cell suspension $(5000$ cells) was seeded into each well of a 96-well plate. The plate was incubated for the indicated time periods (12, $24,36,48,60$ and $72 \mathrm{~h}$ ) in an incubator at $37{ }^{\circ} \mathrm{C}$ in $5 \%$ $\mathrm{CO}_{2}$, and $10 \mu \mathrm{L}$ of CCK- 8 solution was added to each well of the plate. The plate was again incubated for $1 \mathrm{~h}$, and the absorbance at $450 \mathrm{~nm}$ was measured using a microplate reader. Each time point was repeated in three wells, and the experiment was independently performed three times.

\section{Animal study}

This study was evaluated and approved by the Ethics Committee of the Tianjin Medical University Cancer Institute and Hospital, and conducted by skilled experimenters. All applicable international, national, and institutional guidelines for the care and use of animals were followed. Male 5-week-old C57BL/6 mice (SPF Biotechnology Co., Ltd., Beijing, China) were housed in specific pathogen-free conditions. For evaluation of tumour growth in vivo, $1 \times 10^{6}$ cells were suspended in $100 \mu \mathrm{l}$ PBS and injected subcutaneously into the inguinal region of C57 mice. Tumour growth was monitored every 3 days, and a growth curve was drawn from these data. Tumours were measured with fine digital callipers, and tumour volume was calculated by using the following formula: tumour volume $=\left(\right.$ length $\times$ width $\left.^{2}\right) / 2$. After the tumour volume reached approximately $50 \mathrm{~mm}^{3}$, the mice were divided into four groups randomly and injected different solutions into tumours of each group: Control group (50 $\mu \mathrm{l}$ double distilled water), IL-35 group (50 $\mu \mathrm{l}$ rIL-35, $0.25 \mathrm{mg} / \mathrm{ml}$, Sino Biological lnc., China), IL-35
NA group (50 $\mu \mathrm{l} \mathrm{IL-12A,} 0.25 \mathrm{mg} / \mathrm{ml}$, Abcam, USA) and Scramble group (50 $\mu \mathrm{l}$ PBS, ZSJQB Co., Ltd. Beijing., China). Each group had 15 mice, and the survival of the mice was recorded every day. After 2 weeks, all the mice were sacrificed. Isoflurane inhalation was used for anaesthesia. Carbon dioxide asphyxiation followed by cervical dislocation was performed for killing. The tumours were collected, and the tumour volumes were measured. Tumour tissues were dissected and partly formalin fixed and paraffin embedded for immunohistochemistry while the remaining tumours were snap-frozen in liquid nitrogen, then lysed for western blot. The peripheral blood was harvested for ELISA and flow cytometry analysis. Lung tissues were collected and formalin fixed and paraffin embedded for HE staining. Spleens were harvested for flow cytometry analysis.

\section{Measurement of the IL-35 concentrations}

The IL-35 concentrations in plasma were measured by using a commercial mouse IL-35 ELISA kit (Cloud-Clone Corp, Wuhan, People's Republic of China) according to the manufacturer's protocol. Each sample was assayed three times. The minimum detectable dose of this kit is typically less than $3.3 \mathrm{pg} / \mathrm{mL}$.

\section{Detection of lung metastasis}

The excised lung tissues were fixed in $10 \%$ buffered formalin for $48 \mathrm{~h}$ and embedded in paraffin. The lung tissues were sectioned and then stained with HE. Incidence of lung tumour metastasis was examined at day 14 .

\section{Immunohistochemical staining}

Mouse tumour tissues were fixed in $10 \%$ buffered formalin for $48 \mathrm{~h}$ and embedded in paraffin. Sections were deparaffinized and rehydrated. For immunohistochemical staining (IHC), antigen retrieval and endogenous peroxidase inhibition were performed. The sections were then blocked with foetal calf plasma, incubated with mouse anti-p35 antibody (ab66064, Abcam), antiIL12RB2 antibody (ab203209, Abcam), anti-CD31 antibody (ab28364, Abcam), anti-Ki67 antibody (ab15580, Abcam), anti-CD11b antibody (ab133357, Abcam), antiLy6g antibody (ab238132, Abcam), anti-FOXP3 antibody (ab215206, Abcam), anti-CD4 antibody (ab183685, Abcam), and anti-CD8 antibody (ab217344, Abcam), and then with secondary antibody. The sections were visualized with 3,3-diaminobenzidine (DAB) and Mayer's haematoxylin staining. The intensity score was evaluated blindly by three independent observers. The intensity score was defined as $0,1,2,3$, or 4 for negative, weak, moderate, strong or extremely strong staining, respectively. CD31 staining was used to mark the endothelial cells. Large and small microvessels as well as single 
brown immunostained endothelial cells were included in the microvessel count as recommended in consensus guidelines [19]. The microvessel density (MVD) was calculated by determining the average microvessel counts of 10 random fields at $100 \times$ magnification per section. Images were generated using ImageScope Viewer (Leica Biosystems).

\section{Flow cytometry and intracellular staining}

Single-cell suspensions were prepared from the spleens and peripheral blood of mice. Spleens were mechanically disrupted using the plunger end of a $10 \mathrm{ml}$ syringe and resuspended in $1 \%$ FBS/PBS. Peripheral blood in centrifuge tubes was placed into a $4^{\circ} \mathrm{C}$ high speed centrifuge and spun at $1500 \mathrm{rpm}$ for $5 \mathrm{~min}$. The supernatant was frozen at $-20^{\circ} \mathrm{C}$ for subsequent ELISA detection. Then, $2 \mathrm{ml}$ of erythrocyte lysate was added to the precipitate of the centrifuge tube, vibrated and incubated at room temperature for $10 \mathrm{~min}$. Then, the tubes were centrifuged, the supernatant was discarded, and the cells were resuspended in $1 \% \mathrm{FBS} / \mathrm{PBS}$.

Zombie NIR Fixable Viability Kit (Biolegend, USA) were used to stain dead cells. For cell-surface markers, single-cell suspensions were harvested and incubated with anti-mouse/human CD11b-PE, anti-mouse Ly-6G/ Ly-6C (Gr-1)-APC, anti-mouse CD4-FITC, anti-mouse CD8a-PE, anti-mouse CD25-APC, anti-mouse FOXP3PE or appropriate isotype controls (Biolegend, USA) for $30 \mathrm{~min}$ at $4{ }^{\circ} \mathrm{C}$. Fixation buffer was added for $20 \mathrm{~min}$, then cells were resuspended in 1\% PBS. Finally, all samples were analysed by flow cytometry, and data analysis was processed using FlowJo V10 (Treestar, Inc.).

\section{Statistical analysis}

All statistical analyses were carried out by using SPSS 23.0 software (IBM Corporation, Armonk, NY, USA) and GraphPad Prism 7.00 (GraphPad Software, La Jolla,
CA, USA). Data are expressed as the mean \pm standard deviation (SD). Continuous variables were measured by the Kolmogorov-Smirnov test to fit the data to a normal distribution. Student's t-test was used to test parametric data, and Kruskal-Wallis test was used to test nonparametric data. Two-way ANOVA was used to analyse cell growth data. The lung metastasis rate was compared by Fisher's exact test. Two -sided p-values were calculated, and $p<0.05$ was considered statistically significant. Kaplan-Meier curves were analysed for relevant variables. The log-rank test was used to analyse the differences in survival times among different groups. Spearman's correlation analysis was applied to test the correlation of EBI3 and p35 in PCA patients.

\section{Results}

\section{IL-35 expression in PCA cell lines}

First, we investigated the expression of IL-35 in four PCA cell lines, at the same time, to screen the appropriate PCA cell lines for the in vitro study. The two subunits of IL-35 were detectable in all four cell lines, and higher IL-35 levels were observed in PC-3 and RM-1 cells, especially in RM-1 cells. This was verified by western blot (Fig. 1a) and real-time RT-PCR (Fig. 1b). EBI3 was highly expressed in DU145, LNCaP, PC-3 and RM-1 cells, but p35 was only highly expressed in PC-3 and RM-1 cells. Then, we detected the expression of EBI3, p35, p40 (IL-12 is composed of p35 and p40) and p28 (IL-27 is composed of p28 and EBI3). As a result, EBI3 and p35 were high expressed in RM-1 cells, but the expression of p40 and p28 were relatively low (Fig. 1c). Based on the above results, RM-1 cell lines were chosen for subsequent experiments.

\section{IL-35 enhances malignant biological behaviour of RM-1 cells in vitro}

To further investigate the biological behaviour of IL-35 in PCA cells, cell migration, invasion, and proliferation

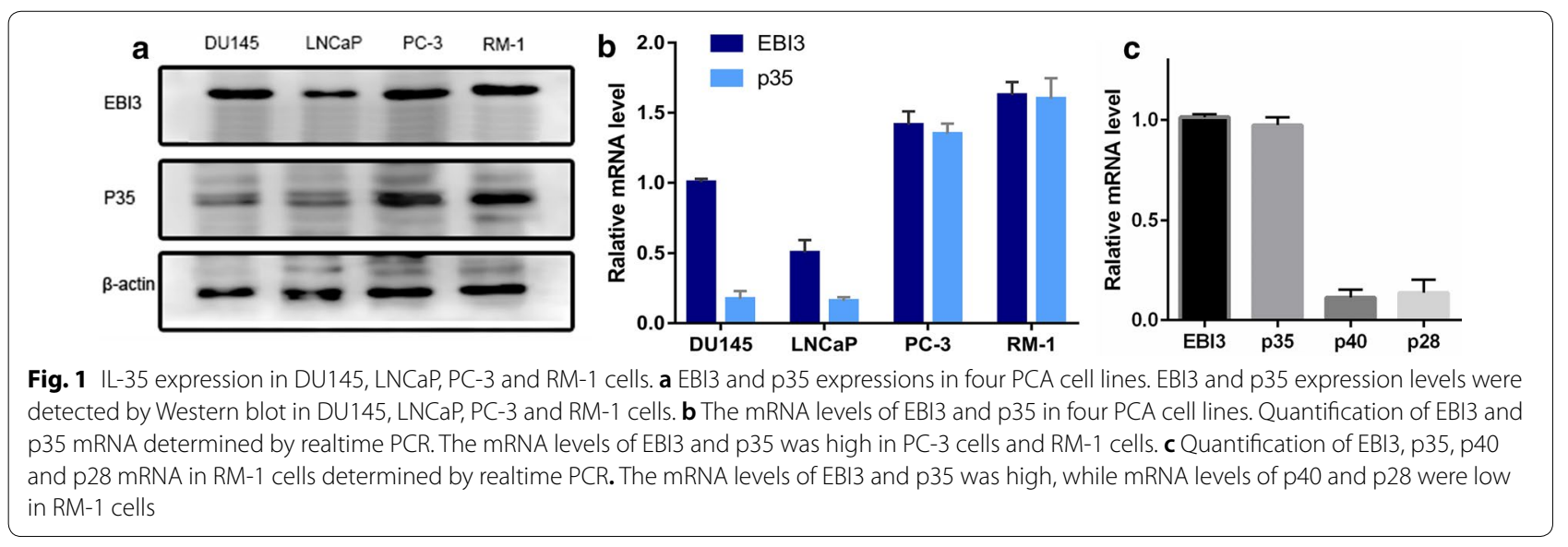


abilities were analysed in RM-1 cell lines. The transwell assay indicated that cell invasion ability increased with rIL-35 protein treatment $(p<0.001)$, but decreased with IL-35 neutralizing antibody treatment $(p<0.001)$ (Fig. 2a, $2 \mathrm{~b})$. We evaluated the migration behaviour of RM-1 cells exposed to IL-35 using a wound healing assay (Fig. 2c). After exposure for $48 \mathrm{~h}$, the percentage of wound closure in IL-35-exposed cells was higher than that in the control $(p=0.0027)$. The migration distance of RM-1 cells treated with IL-35 neutralizing antibody was closer than that of the scramble group $(p=0.0053)$. The CCK- 8 assay was applied to investigate cell proliferation (Fig. 2d). Compared to the negative control group, cell growth was significantly promoted, as evidenced in cells after exposure to rIL-35 protein $(p=0.002)$. Cell growth was remarkably inhibited after IL-35 neutralizing antibody administration using the scramble group as a control $(p=0.0002)$.

\section{IL-35 promotes progression of PCA in vivo}

To investigate the role of IL-35 in tumour growth in mice, a xenograft PCA model was used. Images and growth curves of tumours in four groups are shown in Fig. 3a, b. The tumour volume of mice in the IL-35 group was significantly larger than that in the NC group $\left(1.53 \pm 0.27\right.$ vs. $\left.1.01 \pm 0.22 \mathrm{~cm}^{3} ; p=0.014\right)$, whereas the IL-35 NA group was significantly smaller than that in the scramble group $\left(0.73 \pm 0.11\right.$ vs. $1.04 \pm 0.28 \mathrm{~cm}^{3}$; $p=0.025)$. ELISA results showed that the mean IL-35
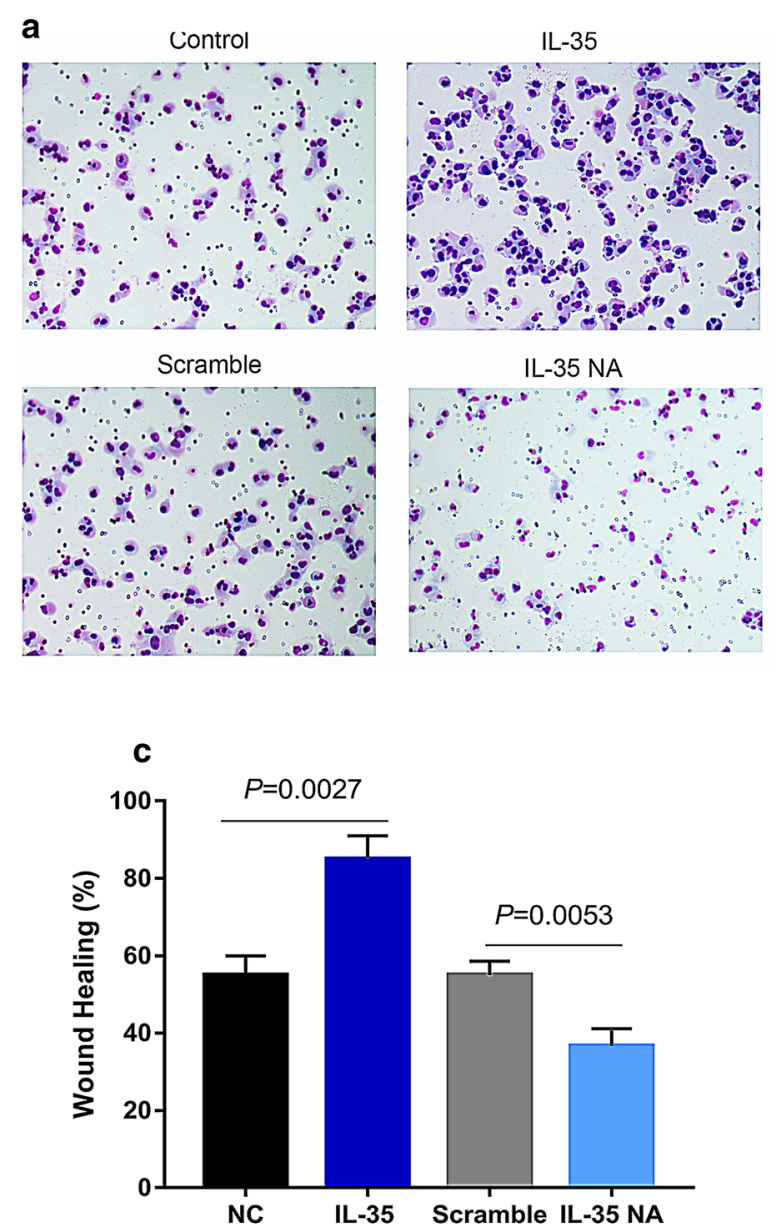
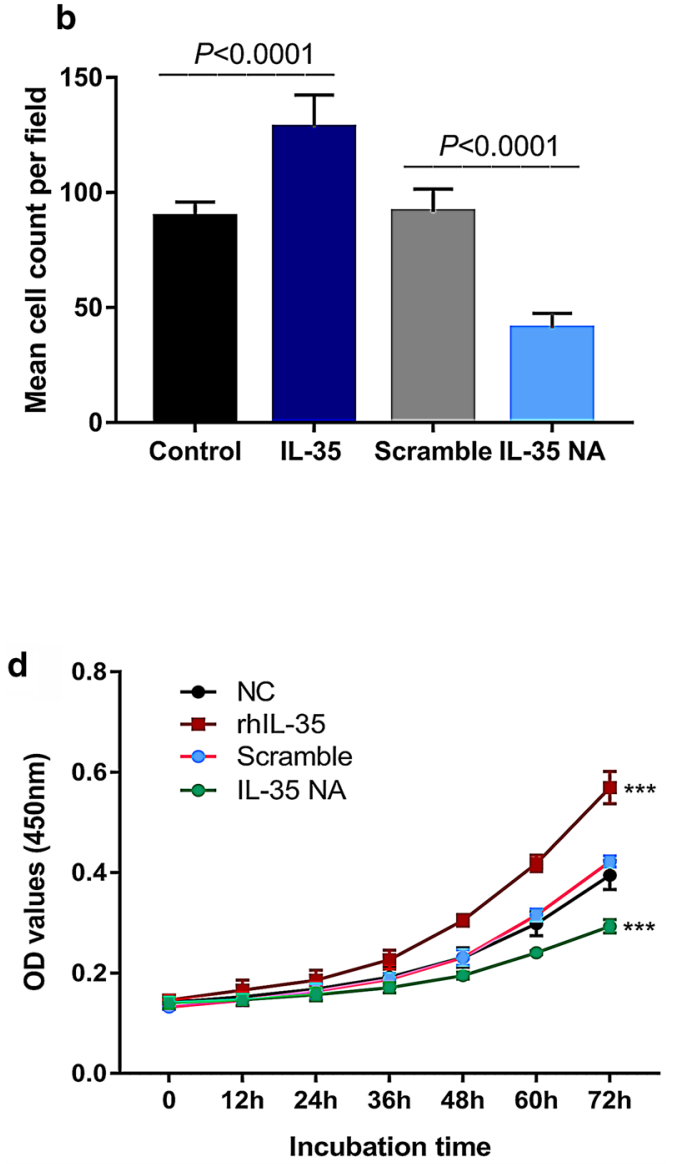

Fig. 2 The invasion, migration and proliferation of RM-1 cells. a The cells that penetrated the matrix-coated membrane. The ability of invasion was examined by transwell assay. $\mathbf{b}$ Mean cell count (per field) that penetrated the matrix-coated membrane. The results are reported as the mean of triplicate assays. IL-35 promoted invasion of RM-1 cells and IL-35 neutralizing antibody decreased RM-1 invasion. c The migration ability of RM-1 cells was detected using the wound healing assay. Cell migration was calculated as the area of cell migration compared to the area of the initial wound. The results are reported as the mean of triplicate assays. $\mathbf{d}$ The proliferation of RM-1 cells were examined by CCK-8 assay. The experiment was independently performed three times. ${ }^{* *} p<0.001$ 


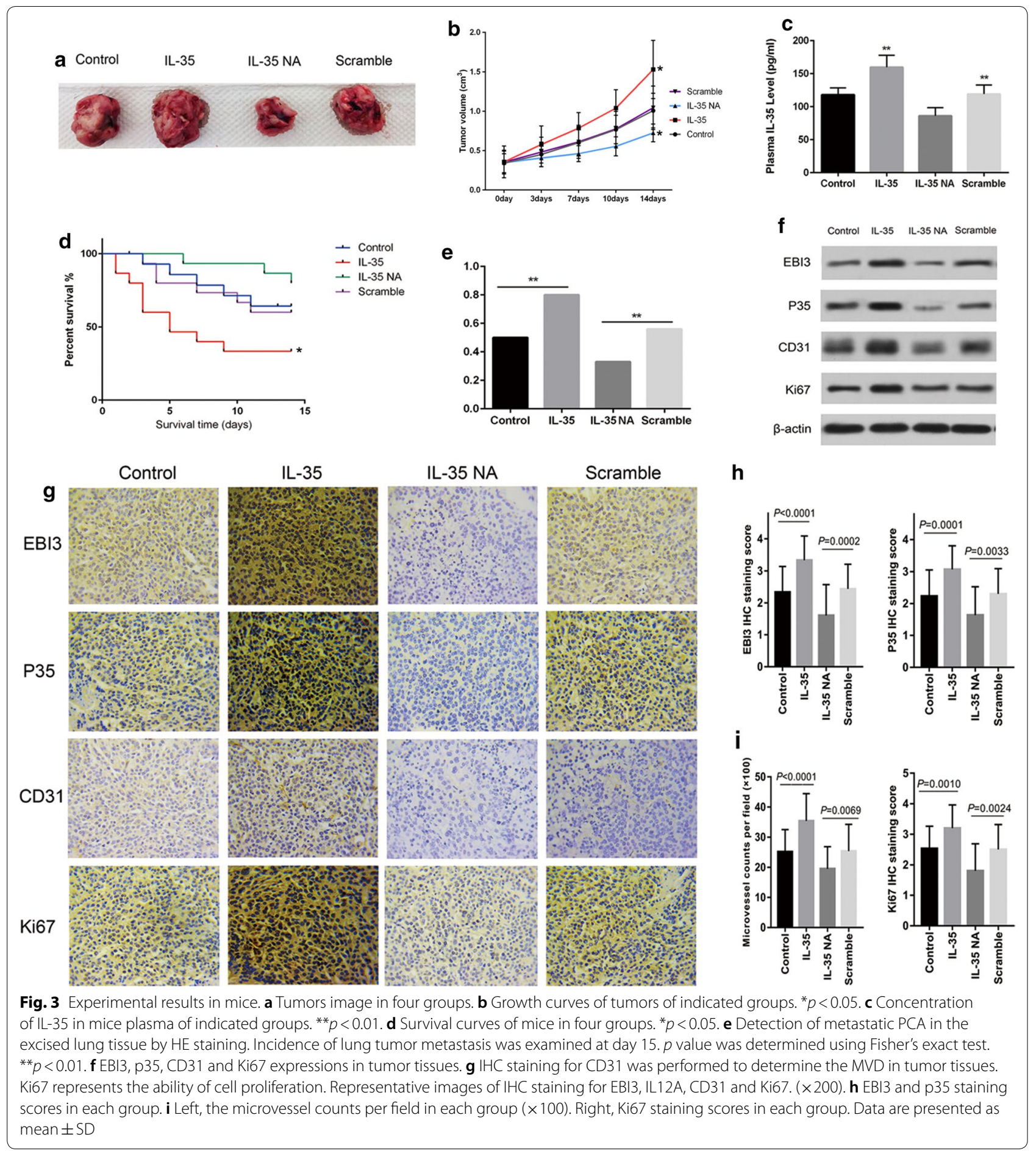

plasma concentration in the IL-35 group was significantly higher than that in the control group $(159.87 \pm 18.02$ vs. $118.37 \pm 10.39 \mathrm{pg} / \mathrm{ml}$, respectively; $p=0.0006$; Fig. 3c), and the mean IL-35 plasma concentration in the IL-35 NA group was markedly lower than that in the scramble group $(86.13 \pm 12.53$ vs. $119.09 \pm 13.70 \mathrm{pg} / \mathrm{ml} ; p=0.0014$;
Fig. 3c). Furthermore, the overall survival rate of the IL-35 group was evidently decreased compared with the control group $(p<0.05)$, but the overall survival rate of the IL-35 NA group was slightly higher than that of the scramble group ( $p=0.18$; Fig. $3 d$ ). In addition, the lung metastasis rate in the IL-35 group was $80.00 \%$, which was 
remarkably higher than that in the control group $(50.00 \%$, $p=0.001)$. The lung metastasis rate in the IL-35 NA group was $33.30 \%$, which was remarkably lower than that in the scramble group (55.56\%, $p=0.002$; Fig. 3e).

\section{IL-35 facilitates angiogenesis and cell proliferation in tumour tissues from mice}

Western blot and immunohistochemistry results indicated that EBI3 and p35 were highly expressed in the tumours of the IL-35 group and less expressed in those of the IL-35 NA group (Fig. 3f-h). A CD31 antibody was used to stain vascular endothelial cells and to calculate the micro vessel density (MVD). The MVD in tumour tissues with high IL-35 levels from the IL-35 group was significantly increased compared with the control group $(35.40 \pm 1.65$ vs $25.17 \pm 1.34 ; p<0.0001 ;$ Fig. $3 i)$. The MVD in tumour tissues with low IL-35 levels from the IL-35 NA group was significantly decreased compared with the scramble group $(19.47 \pm 1.35$ vs $25.37 \pm 1.68$; $p=0.0069$; Fig. 3h). This result was further validated by western blot (Fig. 3f). In addition, Ki67 was highly expressed in the IL-35 group compared with the control group, and less expressed in the IL-35 NA group compared with the scramble group (Fig. 3f, g, i).

\section{IL-35 effects on MDSCs, Tregs, and CD4+ and CD8+T cells in the tumour microenvironment}

The immunohistochemistry results indicated that CD11b, Gr-1 and Foxp3 were highly expressed in the tumours of the IL-35 group and less expressed in those of the IL-35 NA group ( $p<0.01$; Fig. $4 a, b-d)$. CD4 and CD8 were less expressed in the IL-35 group compared with the control group, and highly expressed in the IL-35 NA group compared with the scramble group $(p<0.001$; Fig. 4a, e, f).

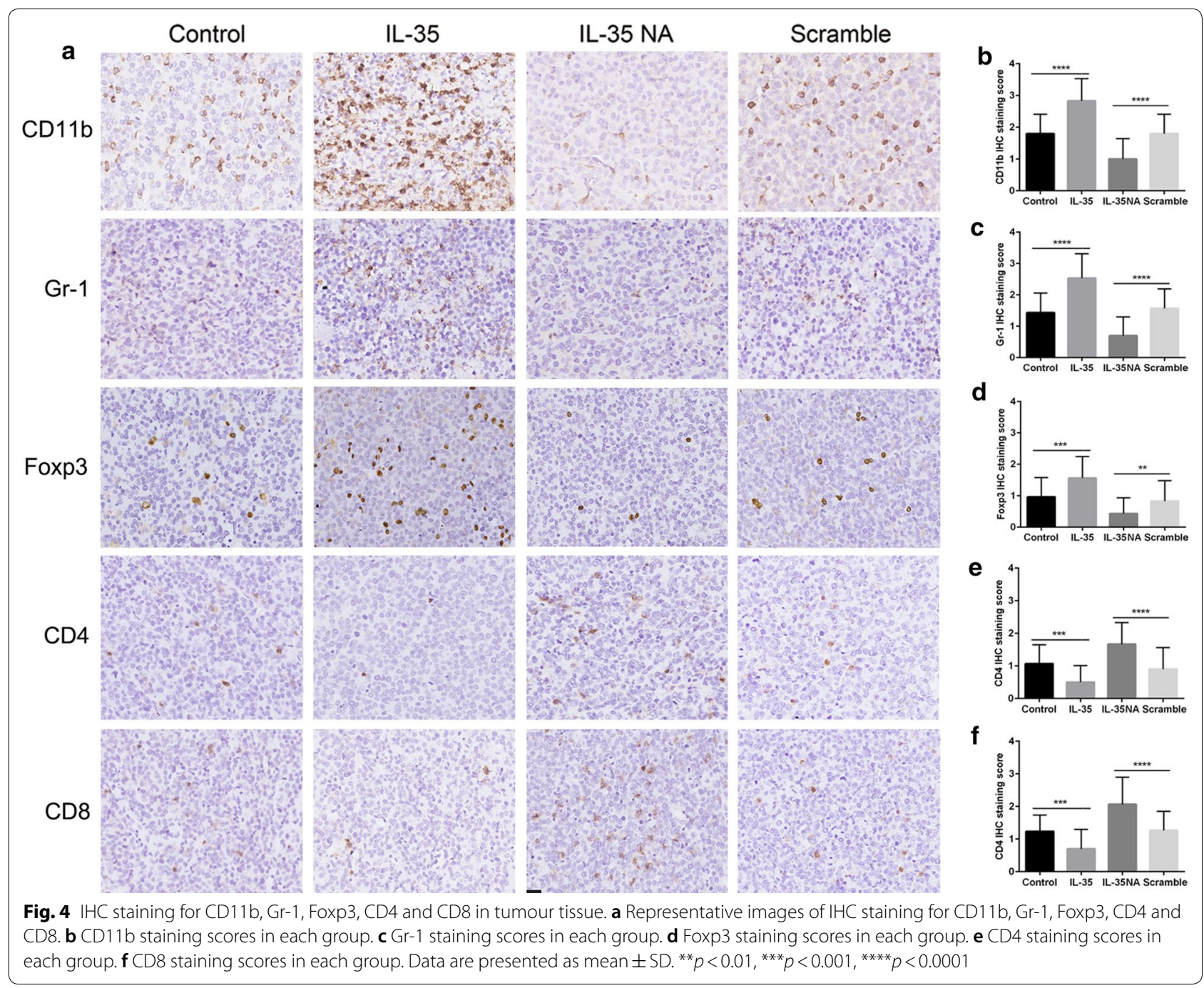




\section{IL-35 effects on MDSCs, Tregs, and CD4+ and CD8+T cells in spleen and blood}

As shown in Fig. 5, we found that high levels of IL-35 significantly increased the proportion of MDSCs in spleen $(30.20 \% \pm 0.96 \% \quad$ vs $20.97 \% \pm 2.27 \% ; \quad p=0.0200)$ and blood $(92.87 \% \pm 0.75 \%$ vs $87.97 \% \pm 0.94 \% ; p=0.0151)$, whereas low levels of IL-35 significantly decreased the proportion of MDSCs in spleen $(6.93 \% \pm 1.05 \%$ vs $21.97 \% \pm 1.70 \% ; p=0.0017)$ and blood $(80.03 \% \pm 1.94 \%$ vs $88.50 \% \pm 1.36 \% ; p=0.0233)$. In addition, the percentage of Treg cells in the IL-35 group was increased in both spleen $(10.36 \% \pm 1.15 \%$ vs $20.97 \% \pm 2.07 \% ; \mathrm{P}=0.0020)$ and plasma $(3.99 \% \pm 0.41 \%$ vs $1.11 \% \pm 0.04 \% ; p=0.0023)$. In the IL-35 NA group, the percentage of Treg cells was evidently decreased in both the spleen $(0.44 \% \pm 0.09 \%$ vs $1.96 \% \pm 0.16 \% ; p=0.0011)$ and plasma $(0.42 \% \pm 0.06 \%$ vs $1.13 \% \pm 0.06 \% ; p=0.0012$ ).

Furthermore, the IL-35 group showed a decrease in $\mathrm{CD} 4+$ and $\mathrm{CD} 8+\mathrm{T}$ cells compared with the control group, and the IL-35 NA group showed an increase in

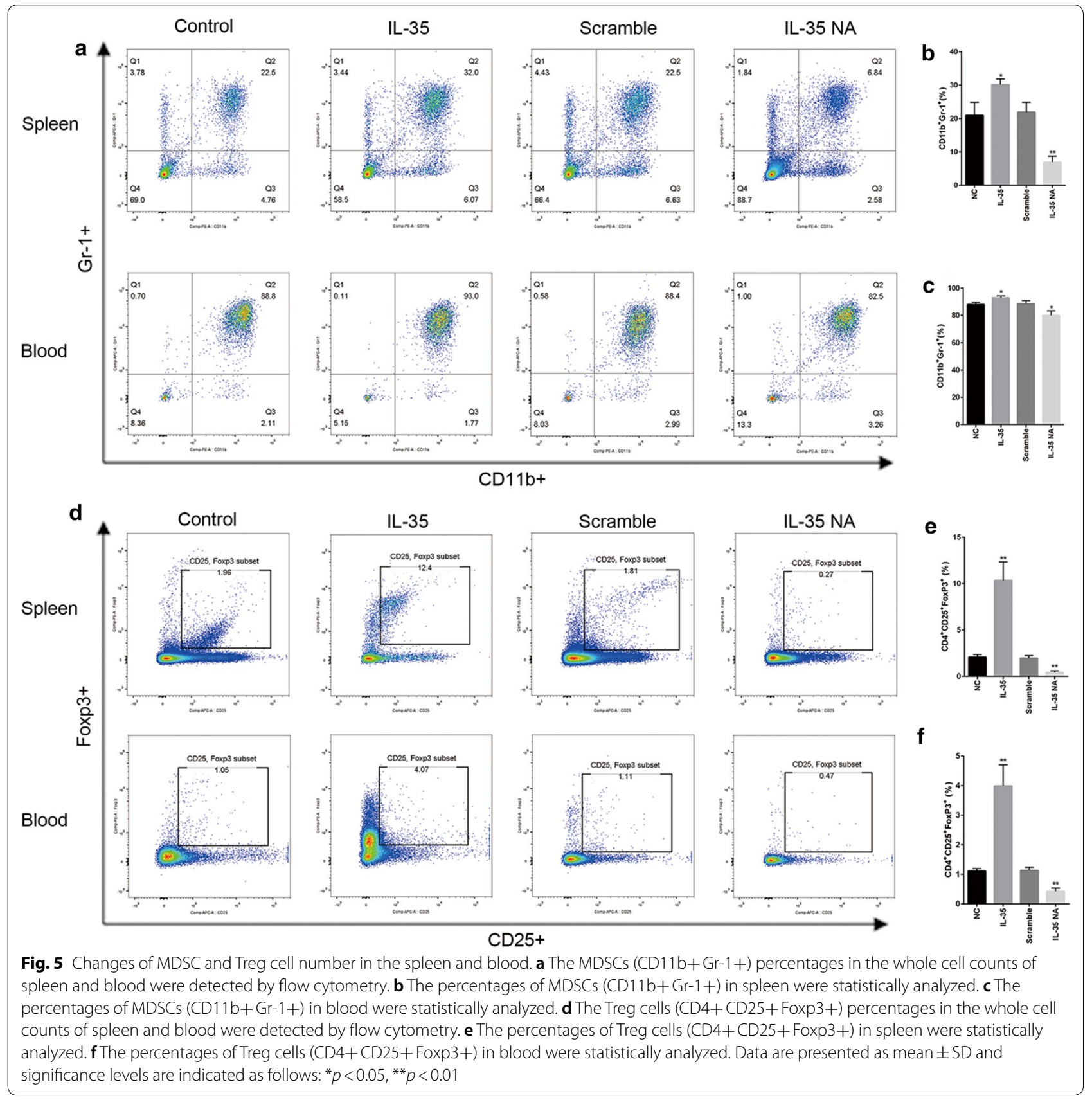


CD4+and CD8+ $\mathrm{T}$ cells compared with the scramble group, both in the spleen and in the blood (Fig. 6).

\section{Discussion}

IL-35 is a member of the IL-12 cytokine family, which has been detected in a variety of diseases and different cell types [20-23]. IL-35 has led many scholars to study its expression regulation, molecular signalling and immunoregulation. Recent studies have shown that IL-35 is overexpressed in a variety of tumours [24-27]. It can be used directly in tumour cells to regulate the expression of related proteins, and it also plays an important role in the occurrence and development of tumours by inducing the production of regulatory $\mathrm{T}$ cells, inhibiting the response of effector $\mathrm{T}$ cells, regulating anti-tumour immune response and inducing immune escape $[10,28$,
29]. Therefore, IL-35 has become a promising biomarker and a target for tumour therapy.

Our previous work showed that plasma IL-35 expression levels in PCA patients were significantly increased compared with those in both patients with benign prostatic hyperplasia and healthy controls [17]. The level of IL-35 was associated with the progression and metastasis of PCA patients [17, 30]. However, the effect of IL-35 on the progression of PCA and its related mechanism are not clear. To the best of our knowledge, this is the first study to detect the effects of IL-35 on the proliferation, metastasis, angiogenesis and prognosis of PCA in vitro and in vivo. In addition, this is also the first exploration into the impact of IL-35 on the immune cells of PCA mice and analysis of the possible mechanisms involved.

In the current study, we first investigated the expression of IL-35 in four kinds of PCA cell lines that were

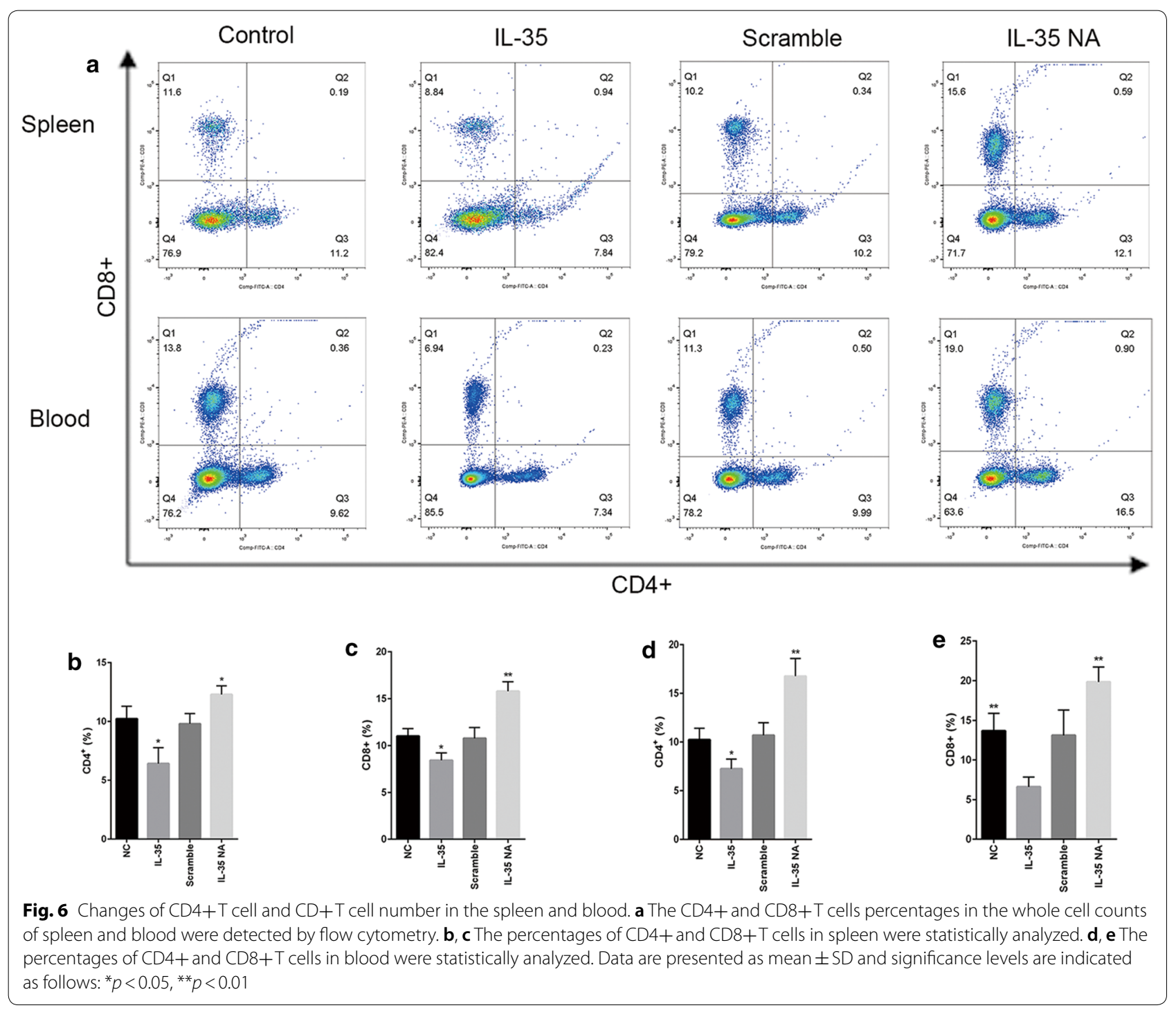


widely used in prostate cancer research, including human PCA cell lines LNCaP, DU145, PC-3, and mouse PCA cell line RM-1. LNCaP was established by Horoszewicz et al. from metastatic lymph nodes of PCA patients in 1980 [31]. It retains the characteristics of the early differentiation function of PCA cells and has the obvious characteristics of androgen-dependent prostate cancer. DU145 was isolated from brain metastases of PCA with a relatively low degree of differentiation and great potential for metastasis [32]. Its androgen dependence needs to be further confirmed [33]. PC-3 was isolated from human PCA bone metastases with low differentiation and no endogenous androgen receptor. It is a non-androgendependent prostate cancer cell with high intensity metastasis potential [32]. In this study, EBI3 and p35 were all highly expressed in PC-3 cells, but only EBI 3 was highly expressed in the hormone-sensitive LNCaP cell line and the moderately malignant DU145 cell line, indicating that IL-35 might be related to the malignancy and progression of PCA.

Next, we treated mouse PCA RM-1 cells with DD water, rIL-35 protein, PBS and IL-35 neutralizing antibody, respectively. We found that IL-35 promoted migration and invasion of RM-1 cells by transwell and wound healing assays. IL-35 neutralizing antibody (anti-IL-12A antibody) suppressed migration and invasion of PCA cancer in vitro. This conclusion was further verified in animal experiments. The lung metastasis rate in the IL-35 group with high plasma IL-35 concentration was significantly higher than that in the control group, while the lung metastasis rate in the IL-35 NA group with low IL-35 concentration was significantly lower than that in the scramble group. Based on the above results in the present study, IL-35 played a role in promoting metastasis of PCA, and it might be a target for reducing metastasis of PCA. Similarly, Huang et al. suggested that IL-35 played an important role in the invasion and metastasis of pancreatic ductal cancer (PDAC) cells [34]. Its mechanism was that IL-35 promoted the overexpression of ICAM1 through the gp130-STAT 1 signalling pathway to improve endothelial adhesion and transendothelial migration of PDAC cells [34].

To explore the influence of IL-35 on the proliferation of PCA, we carried out a CCK- 8 assay in vitro. Our results showed that IL-35 promoted the proliferation of RM-1 cells, and the IL-35 neutralizing antibody played the opposite role. This was further validated in an animal study. High levels of IL-35 promoted the growth of PCA tumours in mice, while reduced IL-35 levels restrained tumour growth in vivo. Additionally, Ki67, which is a marker of cell proliferation, was highly expressed in the tumours of the IL-35 group and was expressed at low levels in the IL-35 NA group. These results suggested that IL-35 facilitated cell proliferation of PCA and that decreasing IL-35 was effective at inhibiting the cell proliferation of PCA in vivo. This result is consistent with other studies about IL-35 in breast, colon and pancreas cancers [35-37].

The results of experiments in vivo showed that the overall survival rate of mice overexpressing IL-35 in blood and tissue was significantly lower than that of the control group, which indicated that Il-35 was of great clinical significance in evaluating the prognosis of PCA. The overexpression of IL-35 in tumour tissue and plasma is closely related to tumour progression and poor prognosis in several kinds of cancers. The high expression of IL-35 in pancreatic ductal adenocarcinoma was positively correlated with TNM stage and vascular invasion [38]. IL-35 was highly expressed in the plasma of patients with non-small cell lung cancer (NSCLC) and negatively correlated with survival time [15]. IL-35 was expressed and secreted in breast cancer cells, which was related to poor prognosis of patients and was an independent prognostic factor [35]. The concentration of serum IL-35 and the presence of IL-35 in tumours were positively correlated with the clinical stage of colorectal tumours [26, 39]. Surgical resection of tumours resulted in a decrease in serum IL-35 concentrations, indicating that this cytokine originated from tumours and could be used as an important biomarker for evaluating tumour progression $[13,39,40]$.

It is generally accepted that tumour angiogenesis is crucial for tumour growth. The CD31 protein is present on endothelial cells in microvessels. High CD31 expression is closely related to advanced disease and poor survival in many kinds of cancers [41, 42]. Our results showed that IL-35 significantly increased the expression of CD31 in prostate cancer tissues of mice compared with the control group. It was suggested that IL-35 might promote the malignant development of PCA by upregulating CD31 expression and promoting tumour angiogenesis. Meanwhile, tumours in mice with low IL-35 expression had fewer CD31 expression. This result showed that anti-IL-35 treatment played an important role in inhibiting tumour angiogenesis. The results of this study are similar to those of Huang Chongbiao et al. in pancreatic cancer [37], but the mechanism is different. They found that IL-35 increased the aggregation of monocytes and the expression of CXCL-1 and CXCL-8, which promoted angiogenesis in pancreatic ductal carcinoma. Combined with gemcitabine, the anti-IL-35 neutralizing antibody could significantly reduce monocyte infiltration, microvessel density and volume of PDAC tumour [37].

Treg cells have a vital effect on inhibiting antitumour immunity by hindering the protective immune surveillance of the tumour, inducing immune escape, and blocking the effective antitumour immune response of 
the tumour-bearing host [4]. In the context of tumours, a large number of Treg cells were often detected, which inhibited or reduced these effector lymphocytes, such as $\mathrm{CD} 4+\mathrm{T}$ cells and $\mathrm{CD} 8+$ cytotoxicity $\mathrm{T}$ lymphocytes (CTL), achieving antitumour immune responses [43-45]. CD4+ T cells were reported to be helper $\mathrm{T}$ cells, which are capable of promoting effective antitumour immune responses. CD8 $+\mathrm{T}$ cells mainly refer to $\mathrm{CTL}$, and the increase of CD8+CTL could kill the tumours efficiently. The results of this study showed that IL-35 could significantly increase the proportion of CD4+ Foxp3+ Treg cells and decrease the proportion of $\mathrm{CD} 4+$ and $\mathrm{CD} 8+\mathrm{T}$ in the spleen, blood and tumour tissue of mice with prostate cancer, indicating that IL-35 could promote CD4+ Foxp3+ Treg cells, inhibiting antitumour immunity and promoting the progression of PCA. The proportion of Treg cells in the IL-35 neutralizing antibody group was decreased, and the proportions of CD4+ and CD8+ T cells were increased significantly, indicating that the IL-35 neutralizing antibody might restrain the progression of PCA by decreasing Treg cells.

MDSCs, known as superantigen-derived cells, played an important role in promoting tumour survival, growth and drug resistance [46]. MDSCs are a group of heterogeneous cells composed of activated immature cells and their precursors. Stimulated by tumour cells and matrixreleased factors, leukocyte precursors cannot differentiate into normal immune cells. MDSCs, as immature cells, could leave their site of origin, migrate throughout the whole body, and mediate immunosuppression [46]. Previous studies have shown that tumour-derived IL-35 could increase the accumulation of CD11+ Gr1+ MDSCs in the tumour microenvironment, thus promoting tumour angiogenesis [9]. The tumour cells treated with IL-35 showed decreased sensitivity to the destruction of CTLs, thus inhibiting anti-tumour immunity [9]. The results of our study showed that IL-35 could significantly increase the proportion of MDSCs in the spleen, blood and tumour tissue of mice with PCA, indicating that IL-35 could promote the proliferation of MDSCs, thus inhibiting anti-tumour immunity and promoting the progression of PCA. The proportion of MDSCs in the IL-35 neutralizing antibody group decreased significantly, indicating that IL-35 might be a new target for the treatment of PCA.

However, there are some limitations in present study. Since no conformational antibodies specific to IL-35 are available at present, we detected the expression of EBI3 and p35 for the IHC staining standing for IL-35. We will do further verification if better IL-35 antibodies are available in the future. Another question is that the ways IL-35 promotes cell proliferation and tumour angiogenesis in PCA are still unclear. We will explore more specific mechanisms in further investigations.

\section{Conclusion}

In conclusion, IL-35 contributed to the progression and metastasis of PCA by promoting cell proliferation and tumour angiogenesis. IL-35 might limit the anti-tumour immune response by upregulating the proportions of Tregs and MDSCs and by reducing the proportions of $\mathrm{CD} 4+$ and $\mathrm{CD} 8+\mathrm{T}$ cells. These findings provide new insight into the function of IL-35 in the progression of PCA and underscore the potential significance of IL-35 as a therapeutic target for PCA.

\section{Abbreviations}

CCK-8: Cell-counting kit-8; CTL: Cytotoxicity T lymphocyte; CXCL: CXC chemokine ligands; EBI3: Epstein Barr virus induced 3; Foxp3: Forkhead box p3; IL: Interleukin; MDSCs: Myeloid-derived inhibitory cells; PCA: Prostate cancer; RPMI: Roswell park memorial institute; RT-PCR: Real-time polymerase chain reaction; SPF: Specific pathogen-free; TGF: Transforming growth factor; Tregs: Regulatory $T$ cells.

\section{Acknowledgements}

We thank Wenwen Yu from department of immunology, Tianjin Medical University Cancer Institute and Hospital, for the support of flow cytometry.

\section{Authors' contributions}

GZ, ZJ and YX conceived and designed the study. ZJ, WY, LD and ZH performed the experiments. ZJ,WY and LD did the statistical analysis and wrote the manuscript. GZ and $Y X$ reviewed and edited the manuscript. All authors read and approved the final manuscript and agree to be accountable for all aspects of the research in ensuring that the accuracy or integrity of any part of the work are appropriately investigated and resolved.

\section{Funding}

This work was funded by: 1. National Natural Science Foundations of China grant (Grant Nos. 81501568 and 81471761); 2. Grants from the Tianjin Science Foundation (Grant No. 18ZXDBSY00090).

Availability of data and materials

The datasets used and/or analyzed during the current study are available from the corresponding author on reasonable request.

\section{Ethics approval and consent to participate}

This study was approved by the medical ethics committee of Tianjin Medical University Cancer Institute and Hospital (Approval number: Ek2015026). All applicable international, national, and institutional guidelines for the care and use of animals were followed.

\section{Consent for publication}

Not applicable.

\section{Competing interests}

The authors declare no conflict of interest.

\section{Author details}

${ }^{1}$ Department of Ultrasound Diagnosis and Treatment, Tianjin's Clinical Research Center for Cancer, Key Laboratory of Cancer Prevention and Therapy, National Clinical Research Center of Cancer, Tianjin Medical University Cancer Institute and Hospital, Tianjin 300060, China. ${ }^{2}$ Department of Radiology, The Second Affiliated Hospital of Zhejiang University School of Medicine, Hangzhou 310000, China. ${ }^{3}$ Department of Geriatrics, Laboratory of Neuro-Trauma and Neurodegenerative Disorders, Tianjin Geriatrics Institute, Tianjin Medical University General Hospital, Tianjin 300000, China. ${ }^{4}$ Department of Interventional Therapy, Tianjin's Clinical Research Center for Cancer, Key Laboratory 
of Cancer Prevention and Therapy, National Clinical Research Center for Cancer, Tianjin Medical University Cancer Institute and Hospital, Huan Hu West Road, Tianjin 300060, China.

Received: 26 June 2020 Accepted: 28 September 2020 Published online: 07 October 2020

\section{References}

1. Bray F, Ferlay J, Soerjomataram I, Siegel RL, Torre LA, Jemal A. Global cancer statistics 2018: GLOBOCAN estimates of incidence and mortality worldwide for 36 cancers in 185 countries. CA Cancer J Clin. 2018;68(6):394-424

2. Paller CJ, Antonarakis ES. Management of biochemically recurrent prostate cancer after local therapy: evolving standards of care and new directions. Clin Adv Hematol Oncol. 2013;11(1):14-23.

3. Pagliuca M, Buonerba C, Fizazi K, Di Lorenzo G. The evolving systemic treatment landscape for patients with advanced prostate cancer. Drugs. 2019;79(4):381-400.

4. Togashi Y, Shitara K, Nishikawa H. Regulatory T cells in cancer immunosuppression - implications for anticancer therapy. Nat Rev Clin Oncol. 2019;16(6):356-71.

5. Chen DS, Mellman I. Oncology meets immunology: the cancer-immunity cycle. Immunity. 2013;39(1):1-10.

6. Behzadi P, Behzadi E, Ranjbar R. IL-12 family cytokines: general characteristics, pathogenic microorganisms, receptors, and signalling pathways. Acta Microbiol Immunol Hung. 2016:63(1):1-25.

7. Collison LW, Workman CJ, Kuo TT, Boyd K, Wang Y, Vignali KM, Cross R, Sehy D, Blumberg RS, Vignali DA. The inhibitory cytokine IL-35 contributes to regulatory T-cell function. Nature. 2007;450(7169):566-9.

8. Olson BM, Sullivan JA, Burlingham WJ. Interleukin 35: a key mediator of suppression and the propagation of infectious tolerance. Front Immunol. 2013;4:315.

9. Wang Z, Liu JQ, Liu Z, Shen R, Zhang G, Xu J, Basu S, Feng Y, Bai XF. Tumor-derived IL-35 promotes tumor growth by enhancing myeloid cell accumulation and angiogenesis. J Immunol. 2013;190(5):2415-23.

10. Turnis ME, Sawant DV, Szymczak-Workman AL, Andrews LP, Delgoffe GM, Yano H, Beres AJ, Vogel P, Workman CJ, Vignali DA. Interleukin-35 limits anti-tumor immunity. Immunity. 2016;44(2):316-29.

11. Nicholl MB, Ledgewood CL, Chen X, Bai Q, Qin C, Cook KM, Herrick EJ, Diaz-Arias A, Moore BJ, Fang Y. IL-35 promotes pancreas cancer growth through enhancement of proliferation and inhibition of apoptosis: evidence for a role as an autocrine growth factor. Cytokine. 2014;70(2):126-33.

12. Zhao Z, Chen X, Hao S, Jia R, Wang N, Chen S, Li M, Wang C, Mao H. Increased interleukin-35 expression in tumor-infiltrating lymphocytes correlates with poor prognosis in patients with breast cancer. Cytokine. 2017:89:76-81.

13. Fu YP, Yi Y, Cai XY, Sun J, Ni XC, He HW, Wang JX, Lu ZF, Huang JL, Cao Y, et al. Overexpression of interleukin-35 associates with hepatocellular carcinoma aggressiveness and recurrence after curative resection. $\mathrm{Br}$ J Cancer. 2016;114(7):767-76.

14. Tao Q, Pan Y, Wang Y, Wang H, Xiong S, Li Q, Wang J, Tao L, Wang Z, Wu F, et al. Regulatory T cells-derived IL-35 promotes the growth of adult acute myeloid leukemia blasts. Int J Cancer. 2015;137(10):2384-93.

15. Gu X, Tian T, Zhang B, Liu Y, Yuan C, Shao L, Guo Y, Fan K. Elevated plasma interleukin-35 levels predict poor prognosis in patients with non-small cell lung cancer. Tumour Biol. 2015;36(4):2651-6.

16. Fan YG, Zhai JM, Wang W, Feng B, Yao GL, An YH, Zeng C. IL-35 overexpression is associated with genesis of gastric cancer. Asian Pac J Cancer Prev. 2015;16(7):2845-9.

17. Zhu J, Yang $X$, Wang $Y$, Zhang H, Guo Z. Interleukin-35 is associated with the tumorigenesis and progression of prostate cancer. Oncol Lett. 2019;17(6):5094-102.

18. Chatrabnous N, Ghaderi A, Ariafar A, Razeghinia MS, Nemati M, Jafarzadeh A. Serum concentration of interleukin-35 and its association with tumor stages and FOXP3 gene polymorphism in patients with prostate cancer. Cytokine. 2019;113:221-7.

19. Dineen SP, Sullivan LA, Beck AW, Miller AF, Carbon JG, Mamluk R, Wong H, Brekken RA. The Adnectin CT-322 is a novel VEGF receptor 2 inhibitor that decreases tumor burden in an orthotopic mouse model of pancreatic cancer. BMC Cancer. 2008;8:352.

20. Dixon KO, van der Kooij SW, Vignali DA, van Kooten C. Human tolerogenic dendritic cells produce IL-35 in the absence of other IL-12 family members. Eur J Immunol. 2015;45(6):1736-47.

21. Shen P, Roch T, Lampropoulou V, O'Connor RA, Stervbo U, Hilgenberg E, Ries S, Dang VD, Jaimes Y, Daridon C, et al. IL-35-producing B cells are critical regulators of immunity during autoimmune and infectious diseases. Nature. 2014:507(7492):366-70.

22. Liu MX, Liu QY, Liu Y, Cheng ZM, Liu L, Zhang L, Sun DH. Interleukin-35 suppresses antitumor activity of circulating CD8(+) T cells in osteosarcoma patients. Connect Tissue Res. 2019;60(4):367-75.

23. Lee CC, Lin JC, Hwang WL, Kuo YJ, Chen HK, Tai SK, Lin CC, Yang MH. Macrophage-secreted interleukin-35 regulates cancer cell plasticity to facilitate metastatic colonization. Nat Commun. 2018;9(1):3763.

24. Wu W, Jiang H, Li Y, Yan MX. IL-35 expression is increased in laryngeal squamous cell carcinoma and in the peripheral blood of patients. Oncol Lett. 2017;13(5):3303-8.

25. Jin L, Xu X, Ye B, Pan M, Shi Z, Hu Y. Elevated serum interleukin-35 levels correlate with poor prognosis in patients with clear cell renal cell carcinoma. Int J Clin Exp Med. 2015;8(10):18861-6.

26. Zeng JC, Zhang Z, LiTY, Liang YF, Wang HM, Bao JJ, Zhang JA, Wang WD, Xiang WY, Kong B, et al. Assessing the role of IL-35 in colorectal cancer progression and prognosis. Int J Clin Exp Pathol. 2013;6(9):1806-16.

27. Mirlekar B, Michaud D, Searcy R, Greene K, Pylayeva-Gupta Y. IL35 hinders endogenous antitumor T-cell immunity and responsiveness to immunotherapy in pancreatic cancer. Cancer Immunol Res. 2018;6(9):1014-24

28. Collison LW, Chaturvedi V, Henderson AL, Giacomin PR, Guy C, Bankoti J, Finkelstein D, Forbes K, Workman CJ, Brown SA, et al. IL-35-mediated induction of a potent regulatory $T$ cell population. Nat Immunol. 2010;11(12):1093-101.

29. Wang HM, Zhang XH, Feng MM, Qiao YJ, Ye LQ, Chen J, Fan FF, Guo LL. Interleukin-35 suppresses the antitumor activity of T cells in patients with non-small cell lung cancer. Cell Physiol Biochem. 2018;47(6):2407-19.

30. Zhou C, Zhang J, Chen Y, Wang H, Hou J. Interleukin-35 as a predictor of prostate cancer in patients undergoing initial prostate biopsy. Onco Targets Ther. 2017;10:3485-91.

31. Namekawa T, Ikeda K, Horie-Inoue K, Inoue S. Application of prostate cancer models for preclinical study: advantages and limitations of cell lines, patient-derived xenografts, and three-dimensional culture of patientderived cells. Cells. 2019;8:74.

32. van Bokhoven A, Varella-Garcia M, Korch C, Johannes WU, Smith EE, Miller HL, Nordeen SK, Miller GJ, Lucia MS. Molecular characterization of human prostate carcinoma cell lines. Prostate. 2003;57(3):205-25.

33. Nagakawa O, Akashi T, Hayakawa Y, Junicho A, Koizumi K, Fujiuchi Y, Furuya Y, Matsuda T, Fuse H, Saiki I. Differential expression of integrin subunits in DU-145/AR prostate cancer cells. Oncol Rep. 2004;12(4):837-41.

34. Huang C, Li N, Li Z, Chang A, Chen Y, Zhao T, Li Y, Wang X, Zhang W, Wang $Z$, et al. Tumour-derived Interleukin 35 promotes pancreatic ductal adenocarcinoma cell extravasation and metastasis by inducing ICAM1 expression. Nat Commun. 2017;8:14035.

35. Hao S, Chen X, Wang F, Shao Q, Liu J, Zhao H, Yuan C, Ren H, Mao H. Breast cancer cell-derived IL-35 promotes tumor progression via induction of IL-35-producing induced regulatory T cells. Carcinogenesis. 2018;39(12):1488-96.

36. Jiang Y, Ma Y, Li R, Sun J. Colon cancer-induced interleukin-35 inhibits beta-catenin-mediated pro-oncogenic activity. Oncotarget. 2018;9(15):11989-98.

37. Huang C, Li Z, Li N, Li Y, Chang A, Zhao T, Wang X, Wang H, Gao S, Yang $S$, et al. Interleukin 35 expression correlates with microvessel density in pancreatic ductal adenocarcinoma, recruits monocytes, and promotes growth and angiogenesis of xenograft tumors in mice. Gastroenterology. 2018;154(3):675-88

38. Jin $\mathrm{P}$, Ren H, Sun W, Xin W, Zhang H, Hao J. Circulating IL-35 in pancreatic ductal adenocarcinoma patients. Hum Immunol. 2014;75(1):29-33.

39. Liang Y, Chen Q, Du W, Chen C, Li F, Yang J, Peng J, Kang D, Lin B, Chai X, et al. Epstein-Barr virus-induced gene 3 (EBI3) blocking leads to induce antitumor cytotoxic t lymphocyte response and suppress tumor growth in colorectal cancer by bidirectional reciprocal-regulation STAT3 signaling pathway. Mediators Inflamm. 2016;2016:3214105. 
40. Zhang $Y$, Sun $H$, Wu H, Tan Q, Xiang K. Interleukin 35 is an independent prognostic factor and a therapeutic target for nasopharyngeal carcinoma. Contemp Oncol (Pozn). 2015;19(2):120-4.

41. Rask L, Hogdall CK, Kjaer SK, Christensen L, Jensen A, Blaakaer J, Christensen IJ, Hogdall EVS. Association of CD31 and p53 with survival of ovarian cancer patients. Anticancer Res. 2019;39(2):567-76

42. Razavi SM, Yahyaabadi R. Comparative study of correlation between angiogenesis markers (CD31) and Ki67 marker with behavior of aggressive and nonaggressive central giant cell granuloma with immunohistochemistry technique. Asian Pac J Cancer Prev. 2018;19(8):2279-83.

43. Williams JB, Horton BL, Zheng Y, Duan Y, Powell JD, Gajewski TF. The EGR2 targets $L A G-3$ and 4-1BB describe and regulate dysfunctional antigen-specific CD8+ T cells in the tumor microenvironment. J Exp Med. 2017;214(2):381-400.

44. Chaudhry A, Rudra D, Treuting P, Samstein RM, Liang Y, Kas A, Rudensky AY. CD4+ regulatory T cells control TH17 responses in a Stat3-dependent manner. Science. 2009;326(5955):986-91.
45. Heim L, Kachler K, Siegmund R, Trufa DI, Mittler S, Geppert Cl, Friedrich J, Rieker RJ, Sirbu H, Finotto S. Increased expression of the immunosuppressive interleukin-35 in patients with non-small cell lung cancer. Br J Cancer. 2019;120(9):903-12.

46. Marvel D, Gabrilovich DI. Myeloid-derived suppressor cells in the tumor microenvironment: expect the unexpected. J Clin Invest. 2015;125(9):3356-64.

\section{Publisher's Note}

Springer Nature remains neutral with regard to jurisdictional claims in published maps and institutional affiliations.
Ready to submit your research? Choose BMC and benefit from:

- fast, convenient online submission

- thorough peer review by experienced researchers in your field

- rapid publication on acceptance

- support for research data, including large and complex data types

- gold Open Access which fosters wider collaboration and increased citations

- maximum visibility for your research: over $100 \mathrm{M}$ website views per year

At BMC, research is always in progress.

Learn more biomedcentral.com/submissions 